\title{
REVIEW
}

\section{The light still shines, but not that brightly? The current status of perinatal near infrared spectroscopy}

\section{S E Nicklin, I A-A Hassan, Y A Wickramasinghe, S A Spencer}

Arch Dis Child Fetal Neonatal Ed 2003;88:F263-F268

Efforts have been made to find new, non-invasive methods for assessing tissue oxygenation and haemodynamics, particularly in the brain of the fetus and the newborn infant. Near infrared spectroscopy (NIRS) is a developmental technique that provides just such a method, allowing calculation of variables such as cerebral blood flow and cerebral blood volume. It can also measure peripheral oxygen consumption. This review is based on our long experience of using NIRS. Basic principles, techniques, validation, and clinical applications are highlighted. Although more than two decades have passed since its introduction, NIRS remains very much a developmental technique, despite technical progression. A great deal more research is required for NIRS to become a routine clinical tool.

See end of article for authors' affiliations

Correspondence to: Dr S A Spencer, Neonatal Unit, North Staffordshire Hospital (City General), Newcastle Road, Stoke on Trent ST4 6QG, UK; andy.spencer@ nstaffsh.wmids.nhs.uk

Accepted 3 September 2002
$\mathrm{K}$ nowledge of basic mechanisms controlling oxygen transport and utilisation is essential in understanding the pathophysiology of many diseases. Maintaining adequate tissue oxygen transport could be considered a primary objective in intensive care management. ${ }^{1}$ Inadequacy of clinical techniques for assessing tissue oxygenation may add to uncertainty surrounding the benefits of treatment modalities in acute life threatening illness.

Cerebral palsy remains a significant problem among very low birth weight (VLBW) survivors ${ }^{2}$ and is strongly associated with white matter infarction. Events such as perinatal asphyxia, hypotension, and septic shock are common, adding to the vulnerability of this population. ${ }^{3}$ Pulse oximetry is commonly used to measure arterial oxygen saturation $\left(\mathrm{SaO}_{2}\right)$, supplemented by intermittent arterial gas estimations, and occasional use of transcutaneous oxygen and carbon dioxide monitors. ${ }^{4}$ Systemic circulation is monitored by electrocardiograph and invasive and non-invasive blood pressure monitors. Despite these measures, all continuously applicable at the cotside, cerebral damage frequently occurs, even in infants whose measured parameters have been stable.

Since conventional methods have failed to provide effective strategies for the prevention of brain injury, new methods for assessing the adequacy of the cerebral circulation, particularly of the fetus and neonate, have been sought. Near infrared spectroscopy (NIRS) allows the noninvasive monitoring of tissue oxygenation and cerebral haemodynamics. The aim of this paper is to review the clinical, research, and technical advances in NIRS over the past 25 years and discuss its potential as a clinically useful monitoring tool.

\section{BACKGROUND}

The use of in vivo NIRS in humans was introduced by Jobsis, in 1977, 5 for non-invasive monitoring of tissue oxygenation, and it was first applied to neonates in $1985 .{ }^{6}$ Although the principles underlying NIRS are relatively straightforward, they are often poorly understood. ${ }^{7}$ Two important phenomena are relied on:

(1) The relative transparency of biological tissue to near infrared (NIR) light

(2) The presence of chromophores (compounds whose absorption of NIR is oxygen status dependent) in tissue.

The chromophore most extensively studied is haemoglobin, although cytochrome $\mathrm{aa}_{3}$ and myoglobin are also significant. All techniques use NIR light (600-900 nm). Within this range deoxyhaemoglobin $(\mathrm{Hb}), \quad$ oxyhaemoglobin $\left(\mathrm{HbO}_{2}\right)$, and oxidised cytochrome $\mathrm{aa}_{3}$ exhibit distinguishable optical absorption characteristics, for example, $\mathrm{Hb}$ absorption peaks at $775 \mathrm{~nm}$, whereas at $800 \mathrm{~nm}$ the absorption of $\mathrm{Hb}$ and $\mathrm{HbO}_{2}$ is identical. The characteristics of light are therefore altered by passage through tissue containing these chromophores.

A typical NIRS trace (fig 1) shows the impact of an episode of deoxygenation. The concentration of $\mathrm{HbO}_{2}$ falls, mirrored by an equal and opposite rise in $\mathrm{Hb}$, provided that the total haemoglobin $(\mathrm{HbT})$ in the tissue remains constant. $\mathrm{HbO}_{2}$ may change because of alterations in haemoglobin saturation or volume, therefore Hbdiff $\left(\Delta\left[\mathrm{HbO}_{2}-\mathrm{Hb}\right]\right)$ is often used to track changes

Abbreviations: $C B F$, cerebral blood flow; $C B V$, cerebral blood volume; CBVR, cerebrovascular reactivity; CNEP, continuous negative extrathoracic pressure ventilation; $\mathrm{CSvO}_{2}$, oxygen saturation of cerebral venous blood; $\mathrm{CW}$, continuous wave; $\mathrm{DO}_{2}$, oxygen delivery; DPF, differential path length factor; $\mathrm{FIO}_{2}$, fractional inspired oxygen concentration; $\mathrm{FOE}$, fractional oxygen extraction; $\mathrm{Hb}$, deoxyhaemoglobin; $\mathrm{HbO}_{2}$, oxyhaemoglobin; Hbdiff, $\Delta\left[\mathrm{HbO}_{2}-\mathrm{Hb}\right] ; \mathrm{HbT}$, total haemoglobin; IM, intensity modulated; IPPV, intermittent positive pressure ventilation; $\mathrm{IVH}$, intraventricular haemorrhage; MRS, magnetic resonance spectroscopy; NIR, near infrared; NIRS, near infrared spectroscopy; $\mathrm{PaCO}_{2}$, partial pressure of carbon dioxide in arterial blood; $\mathrm{PCr}$, phosphocreatine; $\mathrm{Pi}$, inorganic phosphate; $\mathrm{SaO}_{2}$, arterial oxygen saturation; TOI, tissue oxygenation index; TOS, tissue oxygen saturation; TPSF, temporal point spread function; TR, time resolved; VLBW, very low birth weight; $\mathrm{VO}_{2}$, oxygen consumption 


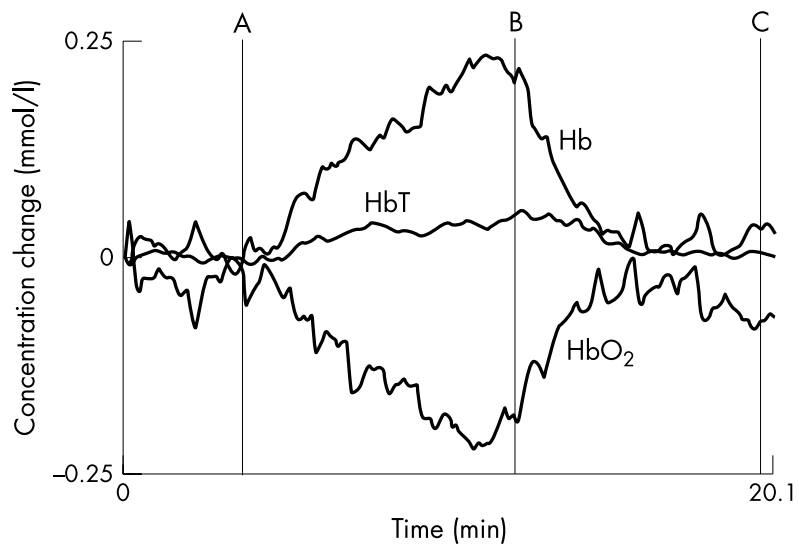

Figure 1 Effects of hypoxia on the concentration of cerebral total $(\mathrm{HbT})$, deoxygenated $(\mathrm{Hb})$, and oxygenated haemoglobin $\left(\mathrm{HbO}_{2}\right)$ in a preterm infant of 30 weeks gestation. ${ }^{13}$ Arterial saturation gradually falls from $94 \%$ at $A$ to a lowest value of $83 \%$ at B, then rises to $93 \%$ at $C$.

attributable to saturation alone. At its most basic, NIRS simply shows changes from baseline, from which all other measurements are derived.

Cytochrome $\mathrm{aa}_{3}$ is also of interest, having the potential to inform about cellular oxygenation. Studies in rats have been successful, $^{89}$ but clinical studies have proven difficult. ${ }^{10}$ Haemoglobin is such a ubiquitous and powerful chromophore that a separate effect of cytochrome $\mathrm{aa}_{3}$ has been difficult to identify.

Myoglobin may be important in muscle studies, where the relative contribution of haemoglobin versus myoglobin remains contentious. ${ }^{11}$

\section{TECHNIQUES USED}

(1) Change in absorbance: "continuous wave (CW) NIRS" uses a series of light pulses of few nanoseconds.

(2) Change in phase, amplitude, and modulation depth: "intensity modulated (IM) NIRS" uses sinusoidal modulation of the light intensity.

(3) Pulse width and transit time: "time resolved (TR) NIRS" uses a picosecond light pulse.

\section{Continuous wave NIR instrument (CWNIRS)}

Initially all NIRS instruments were of this type, applied to animal models at first, then used to study the circulation and oxygenation of the human brain. ${ }^{6}{ }^{12} 13$ The sampling rate is usually 0.5 or 1.0 seconds (for example, Radiometer, Keele, Hammamatsu) although sampling rates of $100 \mathrm{~ms}$ have been achieved and used to study cortical blood oxygenation. Multisite NIRS $^{14}$ enables investigation at four adjacent sites simultaneously (for example, four regions of the brain or two brain and two forearm regions).

Early results ${ }^{62}$ did not adjust the optical pathlength to allow for scattering of light in tissue. Accurate estimates of differential path length factors (DPF) for different tissues were later derived, ${ }^{15}$ enabling quantification of $\Delta \mathrm{Hb}, \Delta \mathrm{HbO}_{2}$, and $\Delta \mathrm{HbT}$ using a multicompartment model. However, this path length is itself altered by haemodynamic changes. Further, attachment method, pressure applied, and gestational age contribute to the errors when assuming a fixed DPF. Probe movement during monitoring may affect the entire study. Remarkably, despite these limitations, NIRS has provided useful evidence regarding the management of sick neonates.

A further problem is that quantifiable changes can only be observed when there is a biochemical or haemodynamic change (spontaneous or induced) in tissue. The clinical drive for absolute values has led to the second generation of NIR instruments. CWNIRS has been adapted in several ways to achieve quantification. ${ }^{16}{ }^{17}$ Somnatics uses a multidistance method to calculate intracerebral oxygen saturation. However, regional measurements in the brains of patients undergoing cardiac surgery correlated poorly with values obtained by co-oximetry. ${ }^{18}$ Critikon uses multiple probes to determine tissue oxygen saturation (TOS). $\triangle \mathrm{TOS}$ in infants was found to correlate with $\Delta \mathrm{SaO}_{2},{ }^{19}$ but $\Delta \mathrm{SaO}_{2}$ was considerably underestimated and a highly significant interpatient variability was observed, leaving the clinical value of TOS measurements undetermined.

\section{Intensity modulated NIR instrument (IMNIRS)}

Further contribution towards quantification of $\mathrm{Hb}$ and $\mathrm{HbO}_{2}$ (hence $\mathrm{HbT}$ and CBV), as well as mixed arteriovenous saturation has come from IMNIR technology. This method calculates coefficients for absorption and scattering, which are required to make absolute measurements. However, artifacts caused by probe movement may affect the calculations. In pulse oximetry, specialised signal processing techniques have reduced this problem. The light intensity varies in amplitude in a sinusoidal manner. The phase, amplitude, and modulation depth of the transmitted/back scattered signal are altered by the tissue. Changes in volume of chromophores will produce changes in the coefficients. ${ }^{20}$

\section{Time resolved type (TRNIRS)}

TRNIRS measures the time passage of a picosecond pulse of light through tissue. This is the temporal point spread function (TPSF), from which the necessary coefficients can be calculated, allowing quantification of oxygenation. ${ }^{21}{ }^{22}$ The need for several wavelengths of this picosecond light source and a fast detector makes this a very expensive technique. It has expanded knowledge of tissue characteristics, but had little clinical impact.

It is now theoretically possible to measure and display tissue saturation (regional, mean, or mixed arteriovenous) as a percentage using CW and IMNIR machines. Saturation is a composite of the blood in the arteries, veins, and capillaries, and the values obtained do not equate to any known technique. IMNIR can also measure absolute concentrations of $\mathrm{Hb}, \mathrm{HbO}_{2}$, and $\mathrm{HbT}$ from which $\mathrm{CBV}$ can be derived. Absolute measurements, made on the assumption of homogeneity of tissue, could however be erroneous, ${ }^{23}$ and the influence of multilayered structures warrants investigation. ${ }^{7}$

\section{Optical imaging}

Several groups are trying to develop a functional or biochemical optical image of the brain. Although resolution is likely to be poor, this could identify areas of hypo/hyperperfusion or relative ischaemia. However, the significant problems of light scattering and image reconstruction must be overcome in order to produce images of complex structures like the neonatal brain. Optical imaging of the brain appears feasible and achievable ${ }^{24}$ but is not yet a practical proposition at the cotside.

\section{INDIRECT MEASUREMENTS USING CWNIRS \\ Cerebral blood flow and volume measurements}

CWNIRS has been used to measure cerebral blood flow (CBF) using $\mathrm{HbO}_{2}$ as a tracer. A sharp rise in $\mathrm{HbO}_{2}$ is induced, by increasing fractional inspired oxygen concentration $\left(\mathrm{FIO}_{2}\right)$, and detected by CWNIRS. CBF is calculated by applying the Fick principle, giving neonatal values of $7-33 \mathrm{ml} / 100 \mathrm{~g} / \mathrm{min} .^{25}$ It is vital that during the manoeuvre $\mathrm{CBF}, \mathrm{CBV}$, and $\mathrm{VO}_{2}$ remain constant. ${ }^{10}$ Unfortunately, this is not always possible to achieve.

CBV can also be estimated using CWNIRS. Quantification is achieved by inducing a fall in $\mathrm{SaO}_{2}$ of $5-10 \%$ over five minutes 
within the range $80-95 \%$, by reducing the $\mathrm{FIO}_{2}$. As with the $\mathrm{CBF}$ method, $\mathrm{CBF}, \mathrm{CBV}$, and $\mathrm{VO}_{2}$ are assumed to remain stable. When $\mathrm{HbO}_{2}$ (or Hbdiff) is plotted against $\Delta \mathrm{SaO}_{2}$ the gradient is proportional to CBV. A mean of $2.22(0.40) \mathrm{ml} / \mathrm{l} 00 \mathrm{~g}$ has been recorded in healthy infants. ${ }^{12} \mathrm{CBV}$ has been shown to decrease significantly during sampling from umbilical artery catheters. ${ }^{26}$

These methods are only applicable to oxygen dependent babies and the required $\Delta \mathrm{SaO}_{2}$ must not affect CBV or CBF, or cause excessive desaturation. Multiple measurements are required because the repeatability is poor. This takes time, as parameters must be allowed to settle between tests. Frequently, in sick babies, changes are required for clinical reasons before the series of tests is complete.

\section{Cerebral venous saturation}

It has been assumed that any change in CBV, induced by jugular occlusion or head tilting, is due to a change in the quantity of blood in the venous sinuses. Therefore, the relative change in $\mathrm{Hb}$ compared with $\mathrm{HbO}_{2}$ can be used to calculate the saturation of cerebral venous blood $\left(\mathrm{CSvO}_{2}\right)$. This methodology has been validated against invasive measurements using venous blood sampled during cardiac catheterisation. ${ }^{27}$ Using NIRS with jugular venous occlusion, $\mathrm{CSvO}_{2}$ and jugular blood flow have been measured in healthy infants. ${ }^{28}$ Mean $\mathrm{CSvO}_{2}$ was $64 \%$, but jugular blood flow was much lower than expected, suggesting a methodological problem.

Low levels of $\mathrm{CSvO}_{2}$ could indicate hypoxic stress and high levels a failure of oxygen uptake, as in cellular energy failure. In conjunction with $\mathrm{SaO}_{2}$ and $\mathrm{CBF}, \mathrm{CSvO}_{2}$ has been used to measure cerebral $\mathrm{VO}_{2}{ }^{29}$ However, this introduces all the limitations of CBF measurements. Fractional oxygen extraction (FOE) is the ratio between $\mathrm{VO}_{2}$ and oxygen delivery $\left(\mathrm{DO}_{2}\right)$. This can be calculated, without measuring flow, using the formula $\mathrm{FOE}=\left(\mathrm{SaO}_{2}-\mathrm{CSvO}_{2}\right) / \mathrm{SaO}_{2}$. Assuming constant cerebral $\mathrm{VO}_{2}$, FOE will rise as $\mathrm{DO}_{2}$ to the brain falls, until maximum oxygen extraction is achieved. Beyond this critical point, further reduction in $\mathrm{DO}_{2}$ will cause reduction in $\mathrm{VO}_{2}$, increasing the risk of lactate production and ischaemic damage.

\section{VALIDATION AND COMPARISONS OF NIRS MEASUREMENTS}

Validation of NIRS measurements is difficult because there is no clinically applicable gold standard. However, CWNIRS has been compared with other methods of assessment of cerebral oxygenation and haemodynamics.

\section{Plethysmography}

Changes in CBV in preterm infants have been validated against strain gauge plethysmography. ${ }^{30} \mathrm{~A}$ strain gauge placed around the infant's head detects changes in occipitofrontal circumference allowing $\triangle \mathrm{CBV}$ to be estimated. A change in CBV induced by bilateral jugular venous occlusion in healthy preterm neonates, with NIRS and strain gauge applied simultaneously, produced two closely related sets of measurements.

\section{Pulse oximetry}

Changes in $\mathrm{SaO}_{2}$ using pulse oximetry have been compared with changes in Hbdiff using NIRS in preterm infants. ${ }^{31}$ During pauses in nasal airflow, a fall in $\mathrm{SaO}_{2}$ was observed in $68 \%$ and a fall in Hbdiff in 56\%. Although the degree of concordance was high for large amplitude changes, in 20\% no fall in Hbdiff occurred despite a fall in $\mathrm{SaO}_{2}$ and in $8 \%$ the converse was true. The authors concluded that both techniques are sensitive to changes in cerebral oxygenation. A fall of Hbdiff $>0.3 \mu \mathrm{mol} / 100 \mathrm{~g}$ brain is likely to be clinically significant and is associated with $\Delta \mathrm{SaO}_{2}$ of about $12 \%$.

\section{${ }^{133}$ Xenon clearance}

This is an established technique for measuring CBF. Comparison of both methods in newborn infant $\mathrm{s}^{32}$ showed a good level of agreement.

\section{Magnetic resonance spectroscopy (MRS)}

MRS can detect secondary energy failure in the asphyxiated neonatal brain. A low ratio of intracellular phosphocreatine to inorganic phosphate (PCr:Pi) indicates a poor prognosis. In a comparison with NIRS, one infant, with severe birth asphyxia, had a marked alteration in cerebral haemodynamics preceding the detection of secondary cerebral energy failure by MRS. ${ }^{33}$ Unfortunately, it has not been possible to use cytochrome $\mathrm{aa}_{3}$ measurements to detect secondary energy failure in human infants, although this has been achieved in neonatal piglets. ${ }^{34}$

\section{CLINICAL APPLICATIONS}

Most clinical work has been undertaken using CWNIRS. Where alternative technology has been employed this is stated.

\section{Apnoea and hypoxia}

In 1985, Jane Brazy published the first study showing that hypoxaemia could be detected in newborn infants using NIRS applied to the cranium. ${ }^{6}$ Further studies indicated that a fall in $\mathrm{SaO}_{2}$ of $5-10 \%$ usually results in a fall in $\mathrm{HbO}_{2}$ and a rise in $\mathrm{Hb}$ and $\mathrm{HbT}$, irrespective of whether the fall in $\mathrm{SaO}_{2}$ was spontaneous or induced, suggesting compensatory vasodilatation. ${ }^{13}$

Subsequent studies confirmed the findings for $\mathrm{Hb}$ and $\mathrm{HbO}_{2}$ but showed much more variable results for $\mathrm{HbT}$, suggesting that a fall in HbT is more likely if there is an obstructive element to the apnoea. ${ }^{35}$ Individual traces have been published clearly showing a fall in HbT with bradycardia, overshooting after recovery. ${ }^{13}$ Cyclical desaturation and reoxygenation of cerebral blood has also been shown during periodic breathing. ${ }^{36}$

\section{Fetal studies}

A non-invasive method of detecting fetal hypoxaemia is an attractive proposition. Initial studies were very encouraging. Oxygen given to mothers could be detected by a rise in Hbdiff in the fetus. ${ }^{37}$ Changes in $\mathrm{Hb}$ and $\mathrm{HbO}_{2}$, resulting from contractions, were used to calculate mean cerebral saturation. It subsequently transpired that similar, contraction induced changes, occurred in a non-viable infant, thus questioning the validity of the calculations. ${ }^{38}$ Currently, NIRS is insufficiently developed to allow evaluation of its use in labour by randomised trials. ${ }^{39}$ However, IMNIRS may permit calculation of cerebral saturation between contractions, potentially detecting significant changes in fetal oxygen status.

\section{Ventilation}

Both intermittent positive pressure ventilation (IPPV) and continuous negative extrathoracic pressure ventilation (CNEP) have been shown to lead to reduced CBV. ${ }^{40}{ }^{41}$ In IPPV, this reduction is attributable to a fall in $\mathrm{HbO}_{2}$, whereas in CNEP it results from a fall in both $\mathrm{HbO}_{2}$ and $\mathrm{Hb}$. This implies that whereas IPPV primarily reduces CBF, CNEP, by reducing intrathoracic pressure, increases cerebral venous drainage. Compared to changes during jugular venous occlusion, or apnoea and bradycardia, these changes are reassuringly small. CNEP requires a neck seal, which could theoretically cause jugular venous occlusion. NIRS has shown that this did not occur in any patients studied. ${ }^{42}$ The effect of endotracheal suction on cerebral haemodynamics has also been studied. As expected, during suction, Hbdiff falls as $\mathrm{SaO}_{2}$ falls. The cerebral haemodynamic effects of suctioning are similar in conventional and high frequency ventilation, ${ }^{43}$ and are significantly less during closed rather than open suction. ${ }^{44}$ 


\section{Surfactant}

The introduction of surfactant brought with it concerns about potential effects on the neonatal brain. ${ }^{45}$ Subsequently, NIRS was used to study these effects. ${ }^{46-48} \mathrm{Hb}$ and $\mathrm{HbO}_{2}$ altered as expected with changes in $\mathrm{SaO}_{2}$. Changes in $\mathrm{CBV}$ were less consistent with studies reporting no change, ${ }^{47}$ an increase, ${ }^{48}$ or an increase or decrease, ${ }^{46}$ with observed changes tending to be transient. Differences could reflect variations in surfactant guidelines.

\section{Drugs}

The vulnerability of the preterm cerebral circulation led researchers to use NIRS to study the effects of drug administration in neonates. Aminophylline was once widely used for the treatment of apnoea of prematurity but is associated with significant changes in $\mathrm{CBV}$ and $\mathrm{CBF}^{49}$ Caffeine, on the other hand, does not affect cerebral haemodynamics ${ }^{50}$ and is now the preferred treatment. ${ }^{51}$ Indomethacin is used for the pharmacological closure of patent ductus arteriosus in preterm infants. A study using NIRS and Doppler ultrasonography suggested that intravenous indomethacin bolus administration is associated with a significant fall in CBV and CBF, persisting for at least 60 minutes..$^{52}$ Ibuprofen is being trialled as an alternative to indomethacin and NIRS has been used to compare the cerebral haemodynamic effects. Unlike indomethacin, ibuprofen has little effect on CBV, CBF, or cerebral oxygen delivery. ${ }^{53}$

\section{Birth asphyxia}

Perinatal asphyxia is a significant cause of neonatal hypoxicischaemic brain injury. Early assessment of severity is important for treatment and prognosis, but can be difficult as signs may develop late. Using NIRS, a raised mean CBV was found in neonates with brain injury. ${ }^{12}$ This finding was confirmed in a more recent study using NIRS to measure cerebral haemodynamics during the first 24 hours following perinatal asphyxia. ${ }^{54}$ Asphyxia was associated with an increase in CBV and $\mathrm{CBF}$ and a significant reduction in cerebrovascular reactivity (CBVR) compared with historical control data. CBVR can be calculated following induction of small changes in partial pressure of carbon dioxide $\left(\mathrm{PaCO}_{2}\right)$ by manipulation of ventilator settings. ${ }^{335}$ CBVR was not predictive and tended to normalise after 24 hours. As a group, patients with poorer outcomes had much higher CBVs, but CBV alone did not reliably predict outcome.

\section{Intraventricular haemorrhage}

Intraventricular haemorrhage (IVH) and periventricular lesions remain a major cause of neurodevelopmental problems in VLBW infants. ${ }^{3}$ It was hoped that NIRS would enable identification of babies at risk of these complications. In extremely preterm infants, low CBF on the first day of life is a risk factor for severe IVH, leading to post-haemorrhagic dilatation and/or haemorrhagic parenchymal infarction. ${ }^{56}$ This supports the hypothesis that cerebral ischaemia is an important predisposing factor in the development of such lesions. However, significant overlap occurred between results in babies without lesions and those with severe lesions.

\section{Hypotension and anaemia}

Cerebral FOE has been used to assess the impact of hypotension and anaemia in preterm infants. ${ }^{57}$ Correcting moderate anaemia with a blood transfusion led to a reduction in FOE. Hypotension did not affect cerebral FOE and the researchers postulated that cerebral $\mathrm{DO}_{2}$ might have been maintained by $\mathrm{CBF}$ autoregulation in these infants. Peripheral FOE was used to determine the need for blood transfusion in VLBW neonates, but $59 \%$ of transfusions given were clinically indicated despite "normal" FOE. ${ }^{58}$
Tissue oxygenation index (TOI)

NIRS has been used to determine cerebral and splanchnic TOI in neonates with surgically proven splanchnic ischaemia and controls with apparently normal abdomens. The TOIs were expressed as a cerebrosplanchnic oxygenation ratio which was significantly lower in affected neonates. ${ }^{59}$

\section{Peripheral oxygen consumption}

Early in circulatory compromise compensatory mechanisms maintain $\mathrm{DO}_{2}$ to vital organs by redistributing blood away from the peripheries. Therefore, assessment of peripheral $\mathrm{VO}_{2}$, by either venous ${ }^{60}$ or arterial occlusion, ${ }^{61}$ may provide an early indication of circulatory compromise. A comparison of these methods in well neonates suggests that the arterial method is more repeatable. The mean value (SD) for $\mathrm{VO}_{2}$ is $1.12(0.25)$ for the arterial and $1.60(0.48) \mathrm{mM} / \mathrm{cm} / \mathrm{min}$ for the venous method. Peripheral $\mathrm{VO}_{2}$ is sensitive to changes in global metabolic rate, limb temperature, ${ }^{62} 63$ and blood pressure ${ }^{60}$ Further clinical evaluation is required to determine whether peripheral $\mathrm{VO}_{2}$ assessment can improve outcome in the critical care setting.

\section{CONCLUSIONS}

NIRS has been used for perinatal applications since 1985. Initially NIRS equipment was scarce but this was overcome and hundreds of studies have since been performed. Used in a research context, NIRS has improved understanding of the cerebral circulation. Studies have been difficult to perform, but scientifically useful information has been obtained regarding the impact of a variety of clinical situations and interventions. The key question now is whether, after such extensive research, NIRS can be absorbed into the routine clinical care of the sick infant.

The promise of a fetal or neonatal "brain monitor" remains unfulfilled. Why has it been so difficult to produce such a monitor? CWNIRS initially struggled with various clinical groups evaluating their own preferred machines without any coordinated trials. The main reason suggested, however, is lack of quantification of brain oxygenation. Monitoring aims to keep parameters within set limits. Even with conventional monitoring, such as blood pressure, these can be difficult to define. $^{3}$

Newer instruments are being developed with the capability of giving quantifiable results, and a small number of clinical studies have been undertaken. However, an evidence base to support the interpretation of the data obtained remains a long way off. At what level should $\mathrm{CSvO}_{2}$ or $\mathrm{CBV}$ be maintained during intensive care? What variations can be allowed? Will maintaining these parameters within set limits improve neurological outcome? Will they provide prognostic information in cerebral compromise and assist in decisions around the use of neuroprotective agents?

It is our opinion, that perinatal NIRS is still very much a developmental technique and, as such, should be used only within clearly defined research programmes. Modern machines may hold considerable promise for the future, as quantification becomes more secure. Hopefully, these instruments will not find their way into routine clinical practice until proper large scale studies have been performed and real benefits shown. Continued international collaboration will be essential to achieve this aim.

\section{ACKNOWLEDGEMENTS}

We acknowledge UK funding organisations, EU Biomed 1 and Biomed 2 , and the efforts of researchers worldwide.

\section{Authors' affiliations}

S E Nicklin, I A-A Hassan, S A Spencer, Neonatology Unit, City General Hospital, Stoke on Trent, UK

Y A Wickramasinghe, Centre for Science and Technology in Medicine, University of Keele, UK 


\section{REFERENCES}

1 Siegemund $M$, van Bommel J, Ince $C$. Assessment of regional tissue oxygenation. Intensive Care Med 1999:25:1044-60.

2 Colver AF, Gibson M, Hey EN, et al. Increasing rates of cerebral palsy across the severity spectrum in north-east England 1964-1993. The North of England Collaborative Cerebral Palsy Survey. Arch Dis Child Fetal Neonatal Ed 2000;83:F7-12

3 Kopelman AE. Blood pressure and cerebral ischaemia in very low birth weight infants. J Pediatr 1990;116:1000-2.

4 Spencer SA, Dimmock PW, Brookfield DSK. Survey into current neonatal practice in relation to preterm monitoring. Journal of Clinical Excellence 2002; 2 : 15-27.

5 Jobsis FF. Noninvasive, infrared monitoring of cerebral and myocardial oxygen sufficiency and circulatory parameters. Science 1977; 198: 1264-6.

6 Brazy JE, Lewis DV, Mitnick MH, et al. Noninvasive monitoring of cerebral oxygenation in preterm infants: preliminary observations. Pediatrics 1985;75:217-25.

7 Owen-Reece H, Smith M, Elwell CE, et al. Near infrared spectroscopy. BrJ Anaesth 1999;82:418-26.

8 Wray S, Cope M, Delpy DT, et al. Characterisation of the near infrared absorption spectra of cytochrome $\mathrm{aa}_{3}$ and haemoglobin for the non-invasive monitoring of cerebral oxygenation. Biochim Biophys Acta 1988;933:184-92

9 Wickramasinghe $Y$, Thorniley $M$, Rolfe $P$, et al. Development of algorithms for in-vivo non-invasive monitoring in biological tissue using near infra-red spectroscopy. Proceedings of the 5th Mediterranean Conference on Medical \& Biological Engineering, 1989:252-3.

10 von Siebenthal K, Bernert G, Casaer P. Near-infrared spectroscopy in newborn infants. Brain Dev 1992;14:135-43.

11 Mancini DM, Bolinger L, Li H, et al. Validation of near-infrared spectroscopy in humans. J Appl Physiol 1994;77:2740-7.

12 Wyatt JS, Cope M, Delpy DT, et al. Quantification of cerebral oxygenation and haemodynamics in sick newborn infants by near infrared spectrophotometry. Lancet 1986;2:1063-6.

13 Livera LN, Spencer SA, Thorniley MS, et al. Effects of hypoxaemia and bradycardia on neonatal cerebral haemodynamics. Arch Dis Child 1991;66:376-80.

14 Lehr HP, Wickramasinghe Y. New prototype NIRS instrument [corrected] to investigate multi-regional cerebral blood and tissue oxygenation and haemodynamics [published erratum appears in Med Biol Eng Comput 2000;38:476]. Med Biol Eng Comput 2000;38:281-6.

15 Wyatt JS, Cope M, Delpy DT, et al. Measurement of optical path length for cerebral near-infrared spectroscopy in newborn infants. Dev Neurosci 1990;12:140-4.

16 Cope M, Delpy DT, Wray S, et al. A CCD spectrophotometer to quantitate the concentration of chromophores in living tissue utilising the absorption peak of water at $975 \mathrm{~nm}$. Adv Exp Med Biol 1989;248:33-40.

17 Matcher SJ, Cooper CE. Absolute quantification of deoxyhaemoglobin concentration in tissue near infrared spectroscopy. Phys Med Biol 1994;39:1295-312

18 Brown R, Wright G, Royston D. A comparison of two systems for assessing cerebral venous oxyhaemoglobin saturation during cardiopulmonary bypass in humans. Anaesthesia 1993;48:697-700.

19 Wolf $M$, von Siebenthal $K$, Keel $M$, et al. Tissue oxygen saturation measured by near infrared spectrophotometry correlates with arterial oxygen saturation during induced oxygenation changes in neonates. Physiol Meas 2000;21:481-91.

20 Chance B, Maris MB, Sorge J, et al. Phase modulation system for dual wavelength difference spectroscopy of hemoglobin deoxygenation in tissues. In: Lakowicz JR, ed. Proceedings SPIE, Time-Resolved Laser Spectroscopy in Biochemistry II 1990; 1 204:481-91.

21 Miwa M, Ueda Y, Chance B. Development of time-resolved spectroscopy system for quantitative noninvasive tissue measurement. In: Chance B, Alfano RR, eds. Proceedings SPIE, Optical Tomography, Photon Migration, and Spectroscopy of Tissue and Model Media: Theory Human Studies, and Instrumentation 1995;2389:142-9.

22 Chance B, Nioka S, Kent J, et al. Time resolved spectroscopy of haemoglobin and myoglobin in resting and ischemic muscle. Ana Biochem 1988;174:698-707.

23 Farrel TJ, Patterson MS, Essenpreis ME, et al. Influence of tissue inhomogeneities on estimates of tissue optical properties obtained from steady-state reflectometry. In: Chance B, Alfano RR, eds. Proceedings SPIE, Optical Tomography, Photon Migration, and Spectroscopy of Tissue and Model Media: Theory, Human Studies, and Instrumentation 1997:2979:335-42

24 Hintz SR, Cheong WF, van Houten JP, et al. Bedside imaging of intracranial haemorrhage in the neonate using light: comparison with ultrasound, computed tomography and magnetic resonance imaging. Pediatr Res 1999;45:54-9.

25 Edwards AD, Wyatt JS, Richardson C, et al. Cotside measurement of cerebral blood flow in ill newborn infants by near infrared spectroscopy. Lancet 1988:2:770-1.

26 Roll C, Hûning B, Käunicke $M$, et al. Umbilical artery catheter blood sampling decreases cerebral blood volume and oxygenation in very low birthweight infants. Acta Paediatr 2000;89:862-6.

27 Yoxall CW, Weindling AM, Dawani NH, et al. Measurement of cerebral venous oxyhemoglobin saturation in children by near-infrared spectroscopy and jugular venous occlusion. Pediatr Res 1995;38:319-23.
28 Buchvald FF, Kesje K, Greisen G. Measurement of cerebra oxyhaemoglobin saturation and jugular blood flow in term healthy newborn infants by near-infrared spectroscopy and jugular venous occlusion. Biol Neonate 1999;75:97-103.

29 Yoxall CW, Weindling AM. Measurement of cerebral oxygen consumption in the human neonate using near infrared spectroscopy: cerebral oxygen consumption increases with advancing gestational age. Pediatr Res 1998;44:283-90.

30 Wickramasinghe YABD, Livera LN, Spencer SA, et al. Plethysmographic validation of near infrared spectroscopic monitoring of cerebral blood volume. Arch Dis Child 1992;67:407-1 1

31 Watkin SL, Spencer SA, Dimmock PW, et al. A comparison of pulse oximetry and near infrared spectroscopy (NIRS) in the detection of hypoxaemia occurring with pauses in nasal airflow in neonates. J Clin Monit 1999;15:441-7.

32 Skov L, Pryds O, Greisen G. Estimating cerebral blood flow in newborn infants: comparison of near infrared spectroscopy and 133Xe clearance. Pediatr Res 1991:30:570-3.

33 Wyatt JS, Edwards AD, Azzopardi D, et al. Magnetic resonance and near infrared spectroscopy for investigation of perinatal hypoxic-ischaemic brain injury. Arch Dis Child 1989;64:953-63.

34 Cooper CE, Springett R. Measurement of cytochrome oxidase and mitochondrial energetics by near-infrared spectroscopy. Phil Trans $R$ Soc Lond B 1997;352:669-76.

35 Jenni OG, Wolf $M$, Hengartner $M$, et al. Impact of central, obstructive and mixed apnea on cerebral hemodynamics in preterm infants. Biol Neonate 1996:70:91-100.

36 Urlesberger B, Pichler G, Gradnitzer E, et al. Changes in cerebral blood volume and cerebral oxygenation during periodic breathing in term infants. Neuropediatrics 2000;31:75-81.

37 Aldrich CJ, Wyatt JS, Spencer JAD, et al. The effect of maternal oxygen administration on human fetal cerebral oxygenation measured during labour by near infrared spectroscopy. Br J Obstet Gynaecol 1994; 101:509-13.

38 Hamilton RJ, O'Brien PM, Wickramasinghe YA, et al. Intrapartum fetal cerebral near infrared spectroscopy: apparent change in oxygenation demonstrated in a non viable fetus. Br J Obstet Gynaecol 1995; 102:1004-7.

39 Mozurkewich E, Wolf FM. Near-infrared spectroscopy for fetal assessment during labour (Cochrane Review). In: The Cochrane Library, Issue 1. Oxford: Update Software, 2002.

40 Palmer KS. The effects of positive and negative pressure ventilation on the neonatal cerebral circulation: a study using near infrared spectroscopy. MD thesis, Nottingham University, 1993.

41 Palmer KS, Spencer SA, Wickramasinghe YABD, et al. Effects of positive and negative pressure ventilation on cerebral blood volume of newborn infants. Acta Paediatr 1995;84:132-9

42 Palmer K, Spencer SA, Wickramasinghe Y, et al. Negative extrathoracic pressure ventilation - evaluation of the neck seal. Early Hum Dev 1994;37:67-72.

43 Kohlhauser C, Bernert G, Hermon M, et al. Effects of endotracheal suctioning in high-frequency oscillatory and conventionally ventilated low birth weight neonates on cerebral hemodynamics observed by near infrared spectroscopy (NIRS). Pediatr Pulmonol 2000;29:270-5.

44 Mosca FA, Colnaghi $M$, Lattanzio $M$, et al. Closed versus open endotracheal suctioning in preterm infants: effects on cerebral oxygenation and blood volume. Biol Neonate 1997:72:9-14.

45 Cowan F, Whitelaw A, Wertheim D, et al. Cerebral blood flow velocity changes after rapid administration of surfactant. Arch Dis Child 1991;66:1105-9.

46 Edwards AD, McCormick DC, Roth SC, et al. Cerebral hemodynamic effects of treatment with modified natural surfactant investigated by near infrared spectroscopy. Pediatr Res 1992;32:532-6.

47 Roll C, Knief J, Horsch S, Hanssler L. Effect of surfactant administration on cerebral haemodynamics and oxygenation in premature infants near infrared spectroscopy study. Neuropediatrics 2000;31:16-23.

48 Dorrepaal CA, Benders M, Steendijk P, et al. Cerebral haemodynamics and oxygenation in preterm infants after low-vs. high-dose surfactant replacement therapy. Biol Neonate 1993;64:193-200.

49 Bucher HU, Wolf $M$, Keel M, et al. Effect of aminophylline on cerebral haemodynamics and oxidative metabolism in premature infants. Eur J Pediatr 1994;153:123-8

50 Dani C, Bertini G, Reali MF, et al. Brain hemodynamic changes in preterm infants after maintenance dose caffeine and aminophylline treatment. Biol Neonate 2000;78:27-32.

51 Steer PA, Henderson-Smart DJ. Caffeine versus theophylline for apnea in premature infants (Cochrane Review). In: The Cochrane Library, Issue 1. Oxford: Update Software, 2002.

52 Liem KD, Hopman JC, Kollee LA, et al. Effects of repeated indomethacin administration on cerebral oxygenation and haemodynamics in preterm infants: combined near infrared spectrophotometry and Doppler ultrasound study [published erratum appears in Eur J Pediatr 1994;153:782]. Eur J Pediatr 1994;153:504-9.

53 Patel J, Roberts I, Azzopardi D, et al. Randomized double-blind controlled trial comparing the effects of ibuprofen with indomethacin on cerebral hemodynamics in preterm infants with patent ductus arteriosus. Pediatr Res 2000;47:36-42.

54 Meek JH, Elwell CE, McCormick DC, et al. Abnormal cerebral haemodynamics in perinatally asphyxiated neonates related to outcome. Arch Dis Child Fetal Neonatal Ed 1999;81:F1 10-15. 
55 Wyatt JS, Edwards AD, Cope M, et al. Response of cerebral blood volume to changes in arterial carbon dioxide tension in preterm infants. Pediatr Res 1991;29:553-7

56 Meek JH, Tyszczuk L, Elwell CE, et al. Low cerebral blood flow is a risk factor for severe intraventricular haemorrhage. Arch Dis Child Fetal Neonatal Ed 1999;81:F15-18.

57 Wardle SP, Yoxall CW, Weindling AM. Determinants of cerebral fractional oxygen extraction using near infrared spectroscopy in preterm neonates. J Cereb Blood Flow Metab 2000;20:272-9.

58 Wardle SP, Garr R, Yoxall CW, et al. A pilot randomised controlled trial of peripheral fractional oxygen extraction to guide blood transfusions in preterm infants. Arch Dis Child Fetal Neonatal Ed 2002;86:F22-7.

59 Fortune PM, Wagstaff M, Petros AJ. Cerebro-splanchnic oxygenation ratio (CSOR) using near infrared spectroscopy may be able to predict splanchnic ischaemia in neonates. Intensive Care Med 2001;27:1401-7.
60 Wardle SP, Yoxall CW, Weindling AM. Peripheral oxygenation in hypotensive preterm babies. Pediatr Res 1999;45:343-9.

61 Hassan IA-A, Spencer SA, Wickramasinghe YA, et al. Measurement of peripheral oxygen utilisation in neonates using near infrared spectroscopy: comparison between arterial and venous occlusion methods. Early Hum Dev 2000;57:21 1-24.

62 Hassan IA-A, Spencer SA, Wickramasinghe YABD, et al. Does an alteration in forearm skin temperature have an effect on forearm and global oxygen consumption in neonates? [abstract]. Proceedings of The Neonatal Society Meeting, London, 2 November 2000.

63 Hassan IA-A, Spencer SA, Wickramasinghe YABD, et al. Implications of changes in global oxygen consumption on peripheral oxygen consumption in neonates [abstract]. Prenatal and Neonatal Medicine 2000;5(suppl 3):33

\section{Clinical Evidence-Call for contributors}

Clinical Evidence is a regularly updated evidence based journal available worldwide both as a paper version and on the internet. Clinical Evidence needs to recruit a number of new contributors. Contributors are health care professionals or epidemiologists with experience in evidence based medicine and the ability to write in a concise and structured way.

Currently, we are interested in finding contributors with an interest in the following clinical areas:

Altitude sickness; Autism; Basal cell carcinoma; Breast feeding; Carbon monoxide poisoning; Cervical cancer; Cystic fibrosis; Ectopic pregnancy; Grief/bereavement; Halitosis; Hodgkins disease; Infectious mononucleosis (glandular fever); Kidney stones; Malignant melanoma (metastatic); Mesothelioma; Myeloma; Ovarian cyst; Pancreatitis (acute); Pancreatitis (chronic); Polymyalgia rheumatica; Post-partum haemorrhage; Pulmonary embolism; Recurrent miscarriage; Repetitive strain injury; Scoliosis; Seasonal affective disorder; Squint; Systemic lupus erythematosus; Testicular cancer; Varicocele; Viral meningitis; Vitiligo

However, we are always looking for others, so do not let this list discourage you.

Being a contributor involves:

- Appraising the results of literature searches (performed by our Information Specialists) to identify high quality evidence for inclusion in the journal.

- Writing to a highly structured template (about 2000-3000 words), using evidence from selected studies, within 6-8 weeks of receiving the literature search results.

- Working with Clinical Evidence Editors to ensure that the text meets rigorous epidemiological and style standards.

- Updating the text every eight months to incorporate new evidence.

- Expanding the topic to include new questions once every 12-18 months.

If you would like to become a contributor for Clinical Evidence or require more information about what this involves please send your contact details and a copy of your CV, clearly stating the clinical area you are interested in, to Claire Folkes (cfolkes@bmigroup.com).

\section{Call for peer reviewers}

Clinical Evidence also needs to recruit a number of new peer reviewers specifically with an interest in the clinical areas stated above, and also others related to general practice. Peer reviewers are health care professionals or epidemiologists with experience in evidence based medicine. As a peer reviewer you would be asked for your views on the clinical relevance, validity, and accessibility of specific topics within the journal, and their usefulness to the intended audience (international generalists and health care professionals, possibly with limited statistical knowledge). Topics are usually 2000-3000 words in length and we would ask you to review between 2-5 topics per year. The peer review process takes place throughout the year, and our turnaround time for each review is ideally 10-14 days.

If you are interested in becoming a peer reviewer for Clinical Evidence, please complete the peer review questionnaire at www.clinicalevidence.com or contact Claire Folkes (cfolkes@bmigroup.com). 